Research Paper

\title{
Web-Based Learning Personalization of Sequential Learning Style Type to Foster Students' Mastery on Concept in Learning
}

\author{
Abdul Haris Indrakusuma ${ }^{1,2}$, Punaji Setyosari ${ }^{2}$, Sulton $^{2}$, Waras $^{2}$ \\ ${ }^{1}$ STKIP PGRI Tulungagung \\ ${ }^{2}$ Instructional Technology-State University of Malang, Indonesia \\ Corresponding Author: Abdul Haris Indrakusuma
}

\begin{abstract}
This research was aimed to see the improvement of students' mastery on concept in learning by using Sequential Learning Style type which was done by combining online instruction and face to face as the supplementary learning. The data was taken from 30 students who took Learning Material Development course in the Information and Technology Education Department of STKIP PGRI Tulungagung in the semester 4 on 2016. This learning was done by using Personalization of WebBased Learning of Sequential Learning Style Type in which Dokeos was chosen as the e-learning program. The data was collected by using Likert scale of four categories, that is, excellent mastery, good mastery, fair mastery and poor mastery. Based on the data collected from the respondents, it can be concluded that students' level of mastery is high. $70 \%$ of the students stated that they have excellent mastery on the material and $30 \%$ of the students stated that they have good mastery on the material. It showed that this strategy can improve the concept of mastery in learning. The finding, therefore, can be used as the basis to develop new strategy in the learning process by using web-based learning personalization
\end{abstract}

Keywords: Web-based learning personalization, Sequential Learning Style, Mastery on Concept

\section{INTRODUCTION}

Web-based learning in education can be explained as the learning process that is done through a computer that is connected to internet and all of the facilities that are usually available in the learning place can be replaced by the function of a system so the learning process can be done anywhere and anytime. Web-based learning can have method as the outcome and as the solution of effective and efficient education. ${ }^{[1]}$

The utilization of web-based learning should use the method as well as procedure to improve the effectiveness of learning system. Meanwhile, the learners should stress on the importance and the need of individual learner which can suit the learner better to learn, process, examine and comprehend the material as well as content in some ways. ${ }^{[2]}$ Therefore, it is important and challenging to solve the problem of individual in the certain learning environment through the use of computer and information technology. ${ }^{[3]}$ In the webbased learning, the learners can suit any learning style of each learner or it is commonly known as personalization of web-based learning.

During the process web-based learning personalization, it is important to give individual learning personalization and characteristics test for individual learners can be used as the way to get the information of each learner. ${ }^{[4]}$ In some past years, the relevant technique to provide 
learning setting which has personalization is suggested to optimize the learning. ${ }^{[5]}$

In conventional web-based learning, learners are given the same material. However, presentation technique is not enough to optimize the study of the learners unless the individual presentation technique. [6] To solve this problem, the researcher proposed the personalization web-based learning technique to identify the characteristics of the learner and then adapt the presentation style on web-based learning or the learning activity that is suitable with learning style. For the example, [7] developed the web-based learning system using level of knowledge or mastery of the learning material as the main factor and reference to adapt the content of web-based learning to be developed. As an effort to improve individual learning, ${ }^{[8]}$ developed the web-based learning system based on individual level of knowledge and level difficulty of the learning material to result on the individual learning content. [2] developed web-based learning system to provide the module for individual presentation to know the learning style and the cognitive style of each learner.

Learning that adapt the learners characteristics gives opportunity to develop individual as well as meet the learners' need. The development of sophisticated web-based technology make the researchers consider doing researches on leaning style on the personalization of web-based learning. One example is the study done by Akbulut \& Cardak. ${ }^{[9]}$ They did an analysis study of Adaptive Educational Hypermedia (AEH), especially on learning style problem. The result of the research showed that $41(58,6 \%)$ suggested adaptive style framework, $12(17,1 \%)$ suggested automatic detection learning style framework and 11 $(15,7 \%)$ chose the effective of AEH learning style framework. Most of the learners $(81,4 \%)$ also focused on the adaptive learning style and the most liked learning style was Felder Silverman learning style, 35 respondents $(50 \%)$.
From the result of the research above, it is known that each learner have different way on learning. The learner with strong preference for certain learning style can have difficulty in studying if it is not compatible with the learning style. Therefore, those with learning style which are not supported by the learning environment may have problem in the learning process. The ideal condition is that each learner have different treatment according to their own learning style. However, it is not easy for the learner to suit to the teaching style in which the learners have different need in studying. The way in the learning process of each learner may suit for a part of the learners with certain learning style and it may not suit for the learners with other learning styles. This condition should not be forced since it relates to the ability of each learner.

Concept in the personalization of web-based learning in this research is that one way to optimize the utilization of webbased learning is by grow the humane characteristic in the presentation of the content that is friendly and understanding to the learners. Personalization of web-based learning is one of the response to the visitors of web-based learning in the form of content presented in an e-learning site that is able to give information based on the preference and learning style of the visitor. This research is aimed to utilize the humane characteristics, that is, learning style in the form of system personalization as the recommendation on material, teaching material or learning material that suit for the user's interest. Because of the humane characteristics, visits on website and the learner dependence will increase and therefore the final goal of web-based learning will be reached.

\section{LITERATURE REVIEW}

\section{Felder Silverman Learning Style}

As it has been written in the introduction section, [9] showed that the learning style that is most liked by the learners is the learning style by Felder 
Silverman. It is chosen by 35 respondents (50\%), followed by cognitive style $(17,1 \%)$, Kolb (8.6\%), VARK $(7,1 \%)$, Honey and Mumford $(5,7 \%)$. The various learning styles for the adaptive learning system are the learning styles that suit the characteristics of the learners. ${ }^{[10]}$ developed adaptive hypermedia learning system that is suitable for the learners with cognitive learning style. It is stressed on the Pask dimension, that is, 1) Holistic, tends to use global approach, examine the relation of various topics from the very beginning of the learning process and concentrate on the effort to make a full image about problem in the beginning process of learning; 2) Serialist, tends to use the "local: approach and focuses on various topics apart from the previous image about the relation among topics. [11] utilized Honey Mumford Learning Style Questionnaire (LSQ) to assess and categorize the learners' learning styles.

The implementation of Felder Silverman learning style like chosen by Franzoni Velazquez, Cervantes Perez \& Assar ${ }^{[12]}$ as the background of their research because it is successfully implemented in previous researches. In the research, the researchers showed that learners should be given permission to choose learning strategy as well as the appropriate material. This approach was suggested to group the learners with the same learning style and use the appropriate learning strategy and material for each group. Commonly, the learners were not able to implement the approach since they have limited time, the appropriate resources are not available, etc. In the experiment, one of the results showed that the learning style facilitate them to have learning experience and the use of various technology showed that learners' learning preference is not limited to certain tools.

Ultanir dan Temel ${ }^{[13]}$ interpreted the instrument of Felder Silverman learning style to know the obstacles and the validity of the instrument in Mersin University Turkey. The result of the research showed the differences among the learning styles based on the field of study of each learner. The finding showed that sensory and level of activity of the learners in Mersin University in a series.

The learning style model from Felder \& Silverman ${ }^{[14]}$ divided the learning styles into four dimensions in which each of them has two learning styles. Two from the four dimensions are the replication of Myers Briggs and Kolb model, that is, 1) Process (Active, reflective), it is also found in Kolb model; 2) Input (Visual, Verbal); 3) Perception (Sensing, Intuitive), it is analogue with the Perception on Myers Brigss and Kolb; 4) Understanding (Sequential, Global). The details of the dimensions of the learning styles of Felder Silverman are shown in table 1.

Table 1. Dimensions of Felder Silverman Learning Style Model

\begin{tabular}{|l|l|l|}
\hline Dimension & Learning Style & Explanation \\
\hline Process & $\begin{array}{l}\text { Active } \\
\text { Reflective }\end{array}$ & How the learners process the information \\
\hline Perception & $\begin{array}{l}\text { Sensing } \\
\text { Intuitive }\end{array}$ & How the learners do perception on information \\
\hline Input & $\begin{array}{l}\text { Visual } \\
\text { Verbal }\end{array}$ & What kind of input of information that is easily accepted by the learners \\
\hline Understanding & $\begin{array}{l}\text { Sequential } \\
\text { Global }\end{array}$ & How the learners reach the mastery or comprehension \\
\hline
\end{tabular}

Felder Silverman learning style model divided the learning style into four dimensions. The learning styles are activereflective learning style, visual-verbal learning style, sensitive-intuitive learning style and sequential-global learning style.

\section{a. Active-Reflective Learning Style (Process Dimension)}

Mental process in which information is converted into knowledge can be grouped into two categories, that is: 
1) Active experimentation is the activities with information such discussing, explaining and experimenting in various ways.

2) Reflective observation is experimenting and manipulating information in introspective way.

Active learner is someone who feels comfortable or better with the active experiment compared to the reflective observation and reflective learner is in the other hand. The active learner tends to master and understand the information by doing activities such as discussing, explaining or experimenting. Reflective learner tend to think by himself in more calm situation. "Let's try and see what will happen" is the sentences by active learner. "Let's think about it first" is the response of reflective learner. Active learner tends to love working in group compared to reflective learner who loves working alone.

\section{b. Sensing-Intuitive Learning Style (Perception Dimension)}

Sensing and intuition relate to how someone tends to feel the world. Sensing is observation, directly see and listen; intuition is perception, it happens indirectly unconsciously such as speculation, imagination and feeling. Someone can use both of them, sensing and intuition, but they tend to be more one side than the other side [14] Sensing learner (sensor) tends to love fact, data and experiments; intuitive learner (intuitor) tends to love principle and theory and tends to love possibilities and relation

Sensor likes to solve problem using standard method and does not like complication and surprise; intuitor likes innovation and does not like repetition. Sensor will be easier to get angry compared to intuitor if he gets examination on material which is not explained explicitly in the class. Sensor tends to be patient on detail and excellent in remembering fact and doing hand work; intuitor can be better in mastering new concept and often more comfortable with abstraction and formula than the sensor. Sensor tends to be practical and careful than the intuitor; intuitor tends to work faster and more innovative than the sensor. Sensor does not like to have class which does not have clear relation with the real world; intuitor does not like to have class which make them to regularly memorize and calculate.

\section{c. Visual-Verbal Learning Style (Input Dimension)}

Visual learner can memorize well what they see like diagram, film and demonstration. Verbal learner can have more from words, from written explanation or statement. Visual learner may easily forgot someone's words. Verbal learner can have a lot of information from discussion and learn effectively by explaining to other people. Many people in the age of university level or order are visual learner, however the learning material is more verbal. Information is presented more verbally like lecture or representation of visual from the verbal information (words and mathematics symbols written in book, handout or whiteboard).

\section{d. Sequential-Global Learning Style (Understanding Dimension)}

Most of formal education uses presentation material with progressive order, chapter by chapter in order. When all of the materials have been discussed, the learners' mastery will be tested and they will forward to the next level. Some of the learners may feel comfortable with this kind of learning, learning sequentially, mastering the material more or less from what have been taught. Others may not be able to learn with this kind of learning. They will be left behind than the others so that they cannot solve the question easily in day, weeks or even months. Until one day when they get "the meaning", they will have imagination on it. After that, they may understand more about the material and they can solve the problems better than the sequential learner. This is called global learner. ${ }^{[14]}$ Sequential learner tends to understand in linier step. Global learner tend to learn in a big jump, learn the material not in order without see the relation until one day they get the meaning. Sequential learner tends to follow 
the steps in order to solve the problem. Global learner can solve complex problem quickly when they get their big picture of them but they are often difficult to explain how they do it.

Felder Silverman learning style model can be used as the learning basis that is adaptive because of the following research:

1) It is successfully implemented many time so that the learner can adapt the material well. ${ }^{[15,16]}$

2) It has been legalized by experts of the field/ pedagogy expert. ${ }^{\text {[17-19] }}$

3) It is very user friendly and it is easily interpreted for the analysis. ${ }^{\text {[20] }}$

4) The amount of the dimensions is in controlled and it can be implemented for real. ${ }^{[16]}$

5) It focuses the implementation on engineering students. ${ }^{[21]}$

\section{Web-Based Learning Personalization}

Utilization of web as the facility to ease the services has been used by institution, organization, community, especially education institution to improve the quality of learning. Even, an individual has already have a website as one of media to give information, communication and interaction. One aspect of development of web application studied is the website personalization. Web personalization is one response to the web visitors to the content presented in a website hoping that it can give suitable content as the visitors' interest. Nowadays, many personalization services are provided by giant website such as My Excite, My Yahoo, My MSN, My Lycos, Amazon so that everyone who once accessed the website will be interested in visiting the website again in the other time and chance. The word 'my' in My excite, My Yahoo, My MSN, My Lycos is meant that the visitor will feel the sense of belonging as it is their own web when they visit the website. Therefore, the sense of belonging to the web will be touched on the personalization aspect.
Web-based personalization is the process to collect and save the information about the visitor's location, analyze the information and based on the analysis send the appropriate information to each visitor in the appropriate time. So, personalization is an effort to give services in the form of application and information is based on the interest, role and need of the web's visitor.

In a web which provides the personalization services, visitors can change or customize the web content such change the color or theme of the website, change the link or navigation button shown or even the site can recognize the visitor in front of it. Therefore, the website can be adaptive to every visitor. The ability of the website to be adaptive to the visitor with various background is one part that will be continually developed in web personalization.

For instance, a website of ecommerce provides and sell various clothes. When you visit the website before you decide to buy clothes, you will be asked to fill in self information profile. You will fill the information such as name, country origin, sex, religion, age and level of income. After that, your data will be saved in the website database and a moment later you will get recommendation of clothes that you can choose based on the data of your income.

The website, further, will offer you the clothes that is suitable for the climate in Indonesia. If you are a moslem girl, you will be offered list of moslem clothes from various brands like you can see in moslem shop such as veil, mukenah, tunic, gloves, shock and the price is in the range of your income. In the same time, in the other part of the world, there is a visitor who fill in the different profile from you. Since she is a career woman with a significant income, the list appeared in the clothes list is the clothes for career women with various accessories and fantatic price. So, in the same, each visitor will see different web content from the same website. This is only a small part of the examples of website application 
development with personalization aspect in it.

Web personalization is categorized into some model, from the very simple into the complex one, ${ }^{[22]}$ that is:

\section{a. Memorization}

As we know from its name, this model is king of personalization that is used to remind and save the information from the visitor. For example, the information about visitor data such as name, age, time of visit will be save in the cookies and the session will be save in the web server. The information, later, will be used by the website to give information to the visitor in the other time.

\section{b. Customization}

Customization is one of personalization that takes the input from the visitors information when they register. Later, the data will be used to customize the structure and content of the website.

\section{c. Guidance or Recommender System}

This personalization model gives recommendation to the visitors as the interest and taste of the visitors.

\section{d. Task Performance Support}

This model engages the client-side system with the help of the software and therefore the visitors will be helped to surf the website as the wanted information.

To do the personalization, the data is needed as the reference to do the personalization. The data can be taken from the visitors, system and data in the website. Following are the data that you can change to do the personalization, ${ }^{[22]}$ that is:

\section{a. Content data}

Content data is the content of your website such as text, image, video, html page and information from the database.

\section{b. Data structure}

Content data is the content of your website such as text, image, video, html page and information from the database.

\section{c. Usage data}

Usage data is the record of visit of the user on the website. Commonly, the data is save in the file log of your web server or even it can be searched from the cookies and session.

d. User profile

User profile is the data of the user or visitor of your website. For example: the data of country origin or continent, level of income, sex, etc. The information about the user can be got explicitly (through registration form in the website) or implicitly (through the user activity and web server).

In making the website personalization, it is needed the following personalization steps:

\section{a. User Profiling Step}

This step is used to get the information about the user or web visitor so that each user will be recorded the data in the database. The data have important role in the personalization process later. The information from the user make the website recognize who the user is, what he likes or dislike and how high his education is. Each visitor has specific information.

In the system journey, the data about the user will be develop and be static and dynamic. The static data is for example the data about sex, country, address, etc. While the dynamic data is data that will be changed during the interaction of the user and the website, age and number of purchasing for example.

\section{b. Information Filtering Step}

Although the information from the visitor are very helpful for the process of personalization, the website is not enough only from the user data. The activity in accessing data in the data can be the information source of personalization.

There are some techniques that can be used to filter the information in activities and interaction between user and website, that is, rule-based filtering, content-based filtering and collaborative filtering.

\section{1) Rule-based filtering}

Rule-based filtering is the technique to define some rule to be fulfilled in the system journey. The rules are defined before the application is implemented. For example, if a visitor decides to buy a printer, the system will give suggestion and recommendation to the visitor to buy paper as well. 
Figure 1 showed the rules are defined before the system gives recommendation to the visitor.

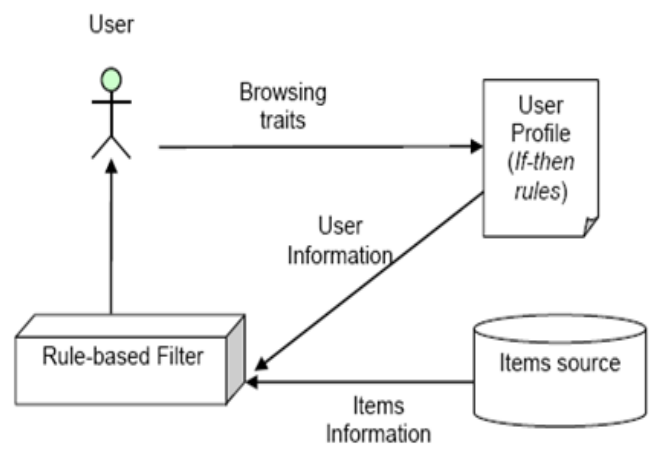

Fig. 1. Rule-based Filtering Design.

2) Content-based filtering

Content-based filtering is also known as item-based filtering, that is do the mechanism in personalization by making the history browsing data and previous purchasing done by the visitors based on certain domain. For example, the visitor once purchased a book with certain topic. The data then will be used as the reference to show book with other topic, writer or price in the range of book previously purchased.

Figure 2 showed the items that have been purchased before and it is become the mechanism to filter the personalization.

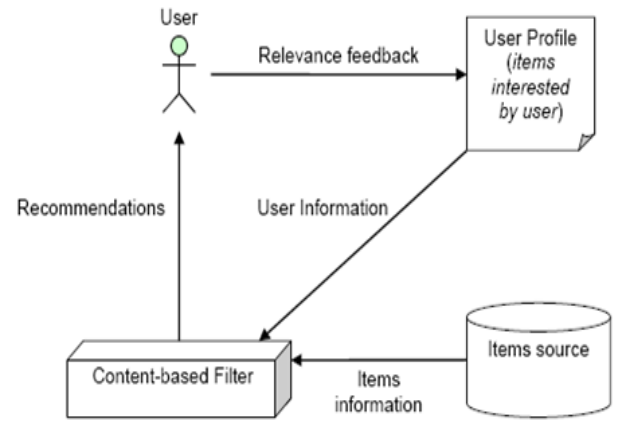

Fig. 2. Content-based Filtering Design.

3) Collaborative filtering

Collaborative filtering is the mechanism in which the same information come from a group of visitor grouped and become the basis in giving recommendation to the visitor with profile similarity.
Collaborative filtering is usually used if the visitor recorded in the system are a lot and have different profiles.

Figure 3 showed that some users have profiles that are grouped into one and become the basis in filtering the information.

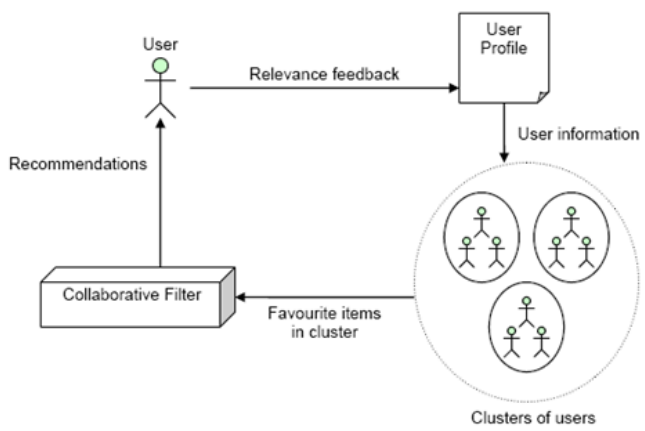

Fig. 3. Collaborative Filtering Design.

\section{Web-Based Learning in The Implementation of E-Learning}

Web-based learning is one of the application in e-learning. E-learning is the process and activity to implement web-based learning, computer based learning, virtual class and digital class. The material in electronic learning is mostly presented through the media of internet, tape video or audio, satellite interactive television broadcasted, or CD-ROM. This definition also stated that the definition of e-learning can be varied depend on the organizer of the e-learning acitivity and how to use it including what the goal of use it is. This definition showed the conclusion that e-learning is the implementation of communication, education and training activity in the form of electronic (http://www.aboutelearning.com/).

learning is different from the conventional learning. Conventional method (lecturing) is used as the oral communication mean between the lecturer and the learners in the learning process. In learning, the history of conventional method is marked as the teacher centered approach. Therefore, the learning process cannot be optimized because the learners will be passive in following the learning activity.

Constructivism learning environment is the learning setting in the 
simultaneous condition. 1) Give the experience in the process of developing knowledge; 2) Give the experience and appreciation on various perspective; 3) Grow the learning in the realistic and relevant context; 4) Raising the sense of belonging and voice in the learning process;

5) Grow the learning in social experience;

6) Raising the use of various kinds of representation; and 7) Raising the selfawareness in the process of getting knowledge (Pepen Permana, 2008).

\section{MATERIALS \& METHODS}

This research implemented the webbased learning personalization of sequential learning style type by utilizing Dokeos. This research is descriptive research which described the data got in the field. Quantitative data is got using likert scale that began from excellent mastery, good mastery, less mastery and poor mastery. To improve the concept mastery, Dokeos is used. The material were provided in the form of power point slide, flip book, online quiz, video and hyperlinks. In the first face to face meeting, the web-based learning personalization was introduced to the students. All of the course material are uploaded by making virtual class group. By making virtual class group, a code was generated so that the students can login and join the virtual class. Assignments and the result of practice were uploaded in the virtual class during the time set by the lecturer.

The research instrument used was adopted the survey developed by Owston and York ${ }^{[23]}$ with some modifications so that it was suitable with the researcher's criteria. This research was done on the students of Technology and Information Education Department STKIP PGRI Tulungagung in semester 42016.

\section{RESULT AND DISCUSSION}

The result of this research described the improvement of the students' mastery on concept in the Material Development course. In the main page of the web-based learning, students were give assignment by the lecturer to learn the material and do practical work and make the report of the practical work to be uploaded in the same page. After the students uploaded the assignment, the lecturer page showed the students who had joined the system or it can be done manually by the lecturer who managed the virtual class. If the students did not submit the work on time, they cannot upload the assignment unless the lecturer did the reconfiguration.

Based on the questionnaire filled by the respondents, the data were as follow: $70 \%$ of the students stated that they improved their mastery on concept into excellent mastery and 30\% stated that they had good mastery. Therefore, web-based learning personalization can support the improvement of students' mastery on concept.

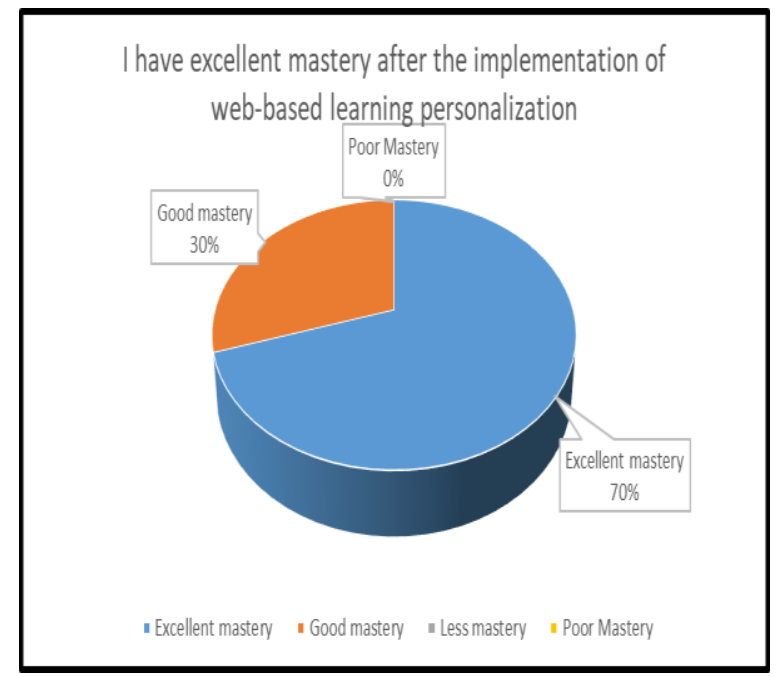

Fig. 4. Students' Mastery on Concept Percentage

\section{CONCLUSION}

Based on the findings and discussion above, it can be concluded that the improvement of students' mastery on concept using web-based learning personalization is high. It can be seen from the respondents' answers that $70 \%$ said they have excellent mastery and $30 \%$ have good mastery.

Based on the conclusion above, it is suggested for the lecturers to follow the development of learning technology especially by utilizing the information 
technology (IT) so that the learning will not be monotone and will be left by the students.

\section{REFERENCES}

1. L. Xlangyang, W. Daoshun, H. Wei, and L. Fenlin, "Blind detection for image steganography: A system framework and implementation,” Int. J. Innov. Comput. Inf. Control, 2009.

2. T. C. Yang, G. J. Hwang, and S. J. H. Yang, "Development of an adaptive learning system with multiple perspectives based on students' learning styles and cognitive styles," Educ. Technol. Soc., 2013.

3. N. Srisawasdi and P. Panjaburee, "Exploring effectiveness of simulationbased inquiry learning in science with integration of formative assessment," J. Comput. Educ., 2015.

4. T. A. Litzinger, S. H. Lee, J. C. Wise, and R. M. Felder, "A psychometric study of the index of learning styles $\subset$," in Journal of Engineering Education, 2007.

5. G. J. Hwang, H. Y. Sung, C. M. Hung, and I. Huang, "A learning style perspective to investigate the necessity of developing adaptive learning systems," Educ. Technol. Soc., 2013.

6. G. Cheng, "Exploring students' learning styles in relation to their acceptance and attitudes towards using Second Life in education: A case study in Hong Kong," Comput. Educ., 2014.

7. K. A. Papanikolaou, M. Grigoriadou, G. D. Magoulas, and H. Kornilakis, "Towards new forms of knowledge communication: The adaptive dimension of a web-based learning environment," Comput. Educ., 2002.

8. S. S. Tseng, J. M. Su, G. J. Hwang, G. H. Hwang, C. C. Tsai, and C. J. Tsai, "An Object-Oriented Course Framework for Developing Adaptive Learning Systems Gwo-Jen Hwang Gwo-Haur Hwang ChinChung Tsai Chang-Jiun Tsai Modular Adaptive Learning System ( MALS )," Framework, 2008.

9. Y. Akbulut and C. S. Cardak, "Adaptive educational hypermedia accommodating learning styles: A content analysis of publications from 2000 to 2011," Comput. Educ., 2012.
10. F. Mampadi, S. Y. Chen, G. Ghinea, and M. P. Chen, "Design of adaptive hypermedia learning systems: A cognitive style approach," Comput. Educ., 2011.

11. Shukr, R. Zainab, and M. H. Rana, "Learning styles of postgraduate and undergraduate medical students," J. Coll. Physicians Surg. Pakistan, 2013.

12. A. L. Franzoni-Velázquez, F. CervantesPérez, and S. Assar, "A quantitative analysis of student learning styles and teacher teachings strategies in a Mexican higher education institution," J. Appl. Res. Technol., 2012.

13. E. Ültanir, Y. G. Ültanir, and G. Örekeci Temel, "The examination of University students' learning styles by means of Felder-Silverman Index," Egit. ve Bilim, 2012.

14. R. M. Felder and L. K. L. Silverman, "Learning and teaching styles in engineering education," Eng. Educ., 1988.

15. H. Hong and Kinshuk, "Adaptation to Student Learning Styles in Web Based Educational Systems," in Ed-Media 2004: World Conference on Educational Multimedia, Hypermedia \& Telecommunications, 2004.

16. P. Paredes and P. Rodriguez, "A Mixed Approach to Modelling Learning Styles in Adaptive Educational Hypermedia," Adv. Technol. Learn., 2005.

17. M. S. Zywno, "A Contribution to Validation of Score Meaning for Felder- Soloman' $\mathrm{s}$ Index of Learning Styles," Eng. Educ., 2003.

18. J. Felder, R. M., \& Spurlin, "Applications, reliability and validity of the index of learning styles," International Journal of Engineering Education 21(1), 2005.

19. T. A. Litzinger, S. H. Lee, J. C. Wise, and R. M. Felder, "A Study of the Reliability and Validity of the Felder-Soloman Index of Learning Styles," in Proceedings of the 2005 American Society for Engineering Education Annual Conference \& Exposition, 2005.

20. P. Ng, J. Pinto, and S. K. Williams, "The effects of learning styles on course performance: a quantile regression analysis," Acad. Educ. Leadersh. J., 2011.

21. M. Héder, "Semantic Web for the Working Ontologist, Second dition: Effective modeling in RDFS and OWL by Allemang Dean and Hendler James, Morgan 
Abdul Haris Indrakusuma et.al. Web-Based Learning Personalization of Sequential Learning Style Type to Foster Students' Mastery on Concept in Learning

Kaufmann, 384 pp., \$55, ISBN 0-12385965-4,” Knowl. Eng. Rev., 2013.

22. O. Nasraoui, "World Wide Web Personalization," in Encyclopedia of Data Warehousing and Mining, 2011.
23. R. Owston and D. N. York, "The nagging question when designing blended courses: Does the proportion of time devoted to online activities matter?" Internet High. Educ., 2018.

How to cite this article: Indrakusuma AH, Setyosari P, Sulton et.al. Web-based learning personalization of sequential learning style type to foster students' mastery on concept in learning. International Journal of Research and Review. 2019; 6(7):535-544. 